\title{
El arte tequitqui como puente \\ intercultural
}

Silvia

Fernández Hernández CEPE-UNAM
Podemos afirmar que el tequitqui ${ }^{1}$ es poco comprendido por los historiadores del arte, a pesar de que su estudio estuvo de moda entre los col onial istas durante décadas. Su escasa fortuna crítica, —según mi parecer-, se debe a una serie de prejuicios y carencias. Término acuñado por J osé Moreno Villa en 1942. Actualmente los colonialistas han abandonado su denominación tequitqui y han adoptado la propuesta de Constantino Reyes Valerio de arte indocristiano. Término con el cual no estoy de acuerdo, pues la designación tequitqui refleja un arte realizado en trabajo colectivo por encargo en una comunidad, concepto que aún preval ece en las comunidades indígenas mexicanas. Reyes Valerio afirma que el arte mudéjar fue realizado por los árabes para los españoles, en cambio los indígenas mexicanos construyeron para "ellos mismos", afirmación que refutaré en el texto. ${ }^{2}$

Intentar comprender una nueva manifestación de arte bajo el cristal occidental, es un prejuicio que no permite hacer juicios acertados, cuando se trata de manifestaciones de arte y de otro circuito. El tequitqui, arte realizado por los indígenas después de la conquista española en el siglo XVI, presupone desde su inicio, un enfrentamiento entre dos culturas, dos formas de pensamiento con profundas diferencias. Porque si consideramos el desarrollo cultural del mundo prehispánico - de acuerdo con lasinvestigaciones de los últimos 40 años-, su cosmología y cosmovisión, fue mucho más cercana al pensamiento Oriental que al Occidental; por otro lado, el desarrollo cultural de los frailes europeos, corresponde al mundo renacentista. Concepciones religi osas opuestas en el que domina una teocracia ani mista mesoamericana y de parte de los frailes europeos el predominio del pensamiento humanista cristiano. Por lo tanto, fueron posiciones irreconciliables de ver la realidad, cuyo resultado fue la des-
1 José Moreno Villa, La escultura colonial mexicana. Vid. Constantino Reyes Valerio, Arte indocristiano, escultura del siglo XVI. 
3 Vid. Roberto Ricard, La conquista espiritual de México.

4 Martha Raquel Fernández García, Historia del concepto de "Arte Tequitqui"; George, Kubler, Arquitectura mexicana del siglo XVI; Manuel, Toussaint, Arte colonial en México; Elisa Vargas Lugo, Las portadas religiosas de México. trucción del otro y la imposición de una nueva cultura traída de mundos lejanos.

Esteenfrentamiento cultural no puede soslayarse, aun considerando la gran cantidad de indígenas que murieron en la guerra de la conquista, sobrevivió una generación de indígenas que fueron sometidos, los cuales vivieron el cambio, la destrucción de su mundo y el inicio de uno nuevo. Es comprensible que el resultado de sus manifestaciones artísticas fueran parte de un gran sincretismo entre ambas culturas.

Pero lo que me sorprende es que se pase por al to una parte tan significativa de la cultura prehispánica como es la escritura pictográfica. Este hecho no se ha considerado por los colonial istas. En la actualidad, la calidad de la información que se tiene respecto al lenguaje escrito y en particular de los glifos y partes ya descifradas por los especial istas, melleva a reflexionar que esa forma de pensamiento pictográfico no desaparece de las mentes indígenas, puesto que su lenguaje está estructurado para expresarse de esa forma, de tal manera que está presente y forma parte importante del arte tequitqui. Sabemos que una parte sustantiva de la comunicación humana radica en la estructura del lenguaje, ya sea verbal o escrita. Si a ello leagregamos - de acuerdo a Robert Ricard ${ }^{3}$-, que no se suprimieron las lenguas nativas como condición para la conquista espiritual, refuerza más el argumento de la importancia dela preservación del pensamiento y estructura lingüística de los indígenas. De tal manera, gran parte del denominado arte tequitqui está manifestando la estructura y forma del pensamiento indígena, por medio de formas expresadas en el lenguaje pictográfico, el cual no desapareció por completo.

Esta omisión de parte de los colonialistas se debe quizás a la especialización que separa tajantemente lo colonial y lo prehispánico; por otro lado, porque ello presupone el conocimiento de la escritura pictográfica, o en su caso, el trabajo interdisciplinario con los lingüistas.

Martha Fernández ${ }^{4}$ al estudiar el estado de la cuestión y la ruta crítica del arte tequitqui, nos presenta un panorama más amplio, del cual podemos llegar a interesantes conclusiones. Un aspecto destacable en la mayoría de los autores como George Kubler, Manuel Toussaint y Elisa 
Vargas Lugo, entre otros, es considerar que el arte del siglo XVI mezcla diferentes estilos, incluso se afirma que son formas híbridas del románico, gótico, plateresco, mudéjar, renacentista y "nativo". Ello presupone que la estructura de los conventos del siglo XVI —que es donde se encuentra principal mente el arte tequitqui-, es desde el punto de vista arquitectónico una solución occidental europea, para el momento de su edificación en la Nueva España, ya se habían terminado de construir las principales iglesias y catedrales en las ciudades europeas, por ello, el repertorio es amplio y la decisión de mezclar las soluciones arquitectónicas y estilísticas provino de los frailes. Esta conclusión conlleva a otra: la técnica constructiva fue la europea no la prehispánica.

La participación indígena no sól o fue en la obra negra dela construcción, sino también en la ornamentación; el arte tequitqui se expresará en ésta última.

Según Martha Fernández todos los cronistas españoles coinciden en quela participación indígena se extendió a todas las artes y queal principio fue voluntaria y entusiasta, afirmación que consi dero debe matizarse, porque después de la brutal conquista militar, humanamente no puede creerse en un "entusiasmo" voluntario ni libre, especialmente si lo verificamos con los estudios de Ricard, Oliva de Coll y Alperovich, ${ }^{5}$ entre otros, respecto a las diferentes formas de resistencia indígena después de la derrota militar.

Los indígenas copiaron los model os occidentales bajo la dirección de los frailes, de acuerdo a las evidencias históricas, al igual que la técnica, -agrega Martha Fernández-, demostraron una gran habilidad en aprender con rapidez, que asombró a los frailes, los cuales el ogiaron siempre su destreza, calificativos que pone en duda Elisa Vargas Lugo, ¿por qué dudar de una capacidad después de siglos de evidencia artística mesoamericana?

Otro aspecto en el que coinciden la mayoría de los autores es que el arte tequitqui no es un estilo propiamente dicho, sino una modalidad ornamental. Considero que el arte tequitqui efectivamente no pudo ser un estilo, porque la concepción del edificio fue europea, pero también por las condiciones de la conquista de los puebl os indígenas, los cual es no eran grupos homogé-
5 J. Oliva de Coll, La resistencia indígena ante la conquista; M. S. Alperovich, "El número de habitantes de México en el periodo colonial", en Ensayos de historia de México. 
neos, aunque existía una cultura dominante la mexica, al arribo de los españoles, su cultura y lengua era distinta, sabemos también que había tres grandes ramas diferentes de escritura pi ctográfica: la mexica, la maya y la mixteca. La erección misma del convento se realizó bajo la dirección y concepción del plan de la conquista espiritual católica, de tal manera, que aunque los indígenas fueran la mano de obra, éstos sólo pudieron expresarse en al gunos aspectos ornamentales del edificio, en las manifestaciones escultóricas o pictóricas como se puede constatar.

Al señalar que se usaron las técnicas europeas en la manufactura de las obras, presupone el manejo de nuevas herramientas, tal es el caso del cambio en la forma de esculpir: no es lo mismo hacerlo piedra contra piedra, que piedra con cincel. J unto con esto se debe considerar que los model os a copiar fueron grabados provenientes de los libros que traían consigo los frailes, así es que copiar de un grabado, - técnica que se encuentra en su inicio-, da por resultado una forma en bajo relieve. Tomando en cuenta estos factores que de ninguna manera son secundarios, resultan injustas las cal ificaciones de Kubler de un arte tosco o "planiforme" como lo denominó Moreno Villa. ${ }^{6}$ La arqueol ogía contemporánea ha demostrado ampliamente el grado de refinamiento de la escultura prehispánica, que contempla desde el bajo hasta el al to relieve, así como la escultura exenta y adosada, que se puede contemplar principal mente en el Museo de Antropología de la ciudad de México. No es que el indígena no supiera escul pir, escul pía de otra forma, con otras herramientas, con otro lenguaje expresivo.

En cuanto a la talla, Martha Fernández y los demás autores no consideran en ella los antecedentes prehispánicos ¿por qué? Si bien los frailes "guiaron" a los indios, éstos eran los que sabían tallar desde antes, con o sin modelo occidental. En tal caso, falta muchísima investigación respecto a los indígenas que participaron, porque no todos fueron a las escuelas de los frailes, muchos debieron de ser mano de obra local. Lo que considero acertado es la distinción que la autora hace de los juicios entre "hacer mal" o "interpretar" un modelo, porque es evidente queel indio interpretó una real idad des- 
conocida en su propia tierra por medio únicamente de imágenes según sus parámetros estéticos más lo nuevo impuesto, ¿qué era lo Occidental para ellos?, el dominio militar y libros con imágenes, ya que nunca conocieron el esplendor europeo de tal cultura, por eso interpretan. Por ello pensar que el espíritu ya no es prehispánico es negar la esencia misma del arte tequitqui, éste ya no prevalece, pero subsiste, claro sólo una parte de ese espíritu, que le denominamos de otra manera para distinguirlo, arte tequitqui, arte sincrético. Afirmar que los indios llegaron a tomar al cristianismo como su propia religión es negar el sincretismo de la primera generación del sigl o XVI. Con el triunfo del clero secular y la generación indígena nacida bajo la nueva realidad del dominio español cristiano, cambiaron las manifestaciones del arte tequitqui. De tal manera que podríamos situarlo en las construcciones de Ios conventos del siglo XVI a partir de 1524 que iniciaron su construcción en el valle de México y terminar el periodo cerca de 1580, con el triunfo del clero secular.

Muy interesante resulta la concepción de J ustino Fernández, ${ }^{7}$ quien concibe al arte tequitqui como un momento en el que se inicia el mestizaje, no sól o racial, sino cultural, de tal manera que se van borrando los límites entre lo extranjero y lo autóctono, para dar paso a la creación propia y original de ese momento. A esta idea Martha Fernández agrega que este arte se encuentra sólo en el siglo XVI. Conclusiones relevantes de ambos autores me llevan a consi derar la hi pótesis de la importancia de la escritura pictográfica en el arte tequitqui, puessi es una manifestación producto del mestizaje, del sincretismo cultural religioso, ¿quiénes pudieron efectuar el sincretismo y por lo tanto el arte tequitqui? únicamente la generación que vivió una parte de su vida en el mundo prehispánico y aprendió su lengua y su escritura pictográfica y sobrevivió a la conquista militar, la cual a su vez aprendió a expresarse con los nuevos símbolos cristianos.

Sin embargo, Martha Fernández ve esas manifestaciones del arte tequitqui como formas aisladas y concluye que son olvidadas, de lo cual difiero. Se manifiestan como lo que realmente son: Ienguaje pictográfico, de aquellos que lo conocían. Por ello considero que el arte tequitqui
7 Justino Fernández, Estética del arte mexicano. 
8 Vid. A Rita Teresita Bermejo Serafín, Manual Gráfico de "Arte Tequitqui" en las esculturas de piedra, de los conjuntos conventuales franciscanos del siglo XVI, en el estado de Puebla.

9 Vid. Los respectivos estudios en Joaquín Galarza, Los códices mesoamericanos; Constantino Reyes Valerio, Arte indocristiano, escultura del siglo XVI. es la expresión de ese puente intercultural, de un lenguaje pictográfico en extinción, que se resiste a morir y que se plasmó de tres formas diferentes principalmente en los conventos del siglo XVI:8

1. Con glifos, claramente reconocibles como: fechas, en Huaquechula, Puebla; vírgula de la palabra; "copillis" como diadema de ángeles y vírgenes; glifo del movimiento "ollín"; toponímicos; flora, en Cal pan, Puebla, en Cholula, el cempasúchil; fauna: águila coronada por una diadema deturquesas "xiuhuitzolli", en el pico lleva un "atl-tlachinolli" símbolo del agua y fuego en Tecamachalco, Puebla; monos en Tlalmanal co en el estado de México, ${ }^{9}$ entre otros.

2. Con formas sincréticasen: vírgenes con una expresión de las manos a la manera de la Coatlicue, o nubes para expresar el "nivel celeste", San Miguel con cascabeles en su vestido o nudos según la usanza de la ropa prehispánica; la sustitución del símbolo del águila guerrera con la figura de ángeles; la perla isabelina por el chalchi huite para simbolizar lo precioso; la flora occidental por la local; el cordón franciscano como el lazo que une a los pueblos en sustitución de la cuerda que ata los años; el agua de la pila bautismal por el agua sagrada que brota de las cuevas; la corona de espinas de Cristo con la forma anudada de la serpiente Quetzal cóatl; el sacrificio humano por el sacrificio de Cristo; Ios emblemas de las órdenes religiosas por los escudos "chimallis" guerreros; escenas de guerreros prehispánicos en las famosas pinturas del convento de Ixmiquilpan, Hidalgo.

3. La interpretación de los grabados europeos sin un concepto de perspectiva renacentista, sino de acuerdo a su tradición de sobreposición de elementosque en al gunos casos denotan desproporciones o incomprensiones de la imagen que se copia. Martha Fernández denomina "Talla plana" en Huaquechula, Puebla, como resultado de la copia de grabados, con lo cual coincido e inclusive, ella agrega que no se puede concluir que esa talla es culta o popular. Respecto a la talla de estas figuras, Constantino Reyes Valerio le denomina "Planiforme" como una mez- 
cla de lo prehispánico y lo mudéjar, con lo cual estoy en desacuerdo, por lo ya expresado. Ellos copiaron grabados e interpretaron lo que entendieron de los grabados, de una iconología y cultura ajenas.

Rita Bermejo, al estudiar los 15 conventos del sigl o XVI de la región del valle de México y Puebla de las fundaciones franciscanas localizó de las tres modalidades que hemos señalado 479 ejemplos, entre ellas 40 glifos prehispánicos claramente reconocibles y el restante 76 por ciento corresponde a las formas sincréticas. Si sumamos las encontradas por Kubler y las de Constantino Reyes Valerio y las de los investigadores del INAH, podremos concluir que las manifestaciones del arte tequitqui no son el ementos aislados si no que forman parte importante de la ornamentación de dichos conventos. Fal ta por lo tanto hacer un compendio de todos los conventos del siglo XVI, con un trabajo interdisci plinario de los especial istas tanto en arte prehispánico como virreinal, ya que con los el ementos encontrados y clasificados adecuadamente, podemos decir que el arte tequitqui es engl obar un conjunto ornamental, los cuales deben diferenciarse como propuse anteriormente.

Por lo tanto, los pueblos indígenas no se desprendieron de su marco cultural al efectuar el trabajo de los conventos del siglo XVı para el clero regular de losfrailesfranciscanos, agustinos y dominicos; utilizaron elementos de su escritura pictográfica, la cual quedó plasmada en gl ifos, colores, imágenes, que reflejan el sentido de su cosmovisión y el sincretismo.

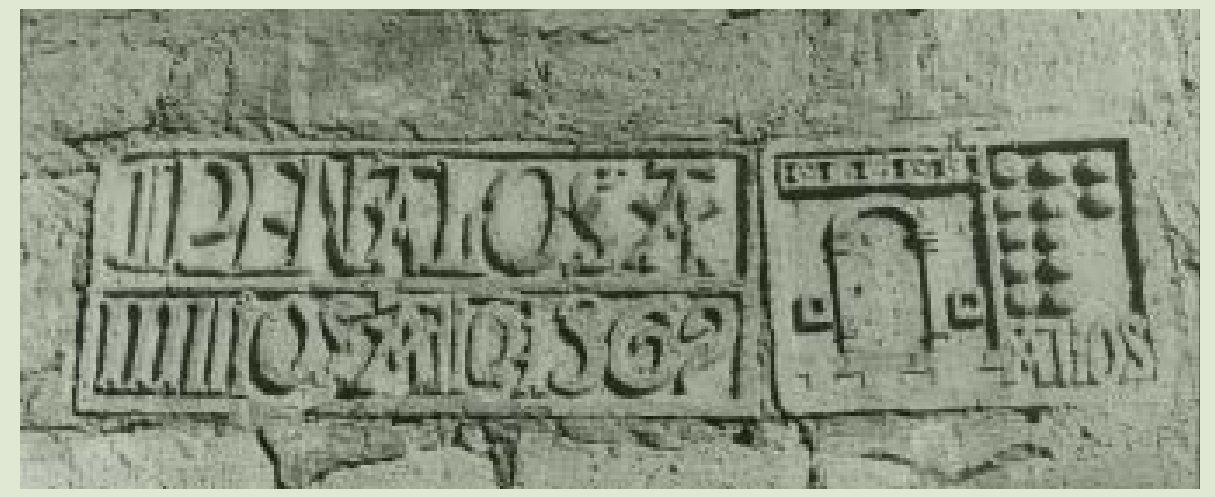


J uzgar una parte del arte tequitqui como tosco y plano, es no comprender el proceso de sincretismo que se efectuaba entre dos culturas diametral mente opuestas, de lo cual derivó una interpretación diferente.

El arraigo milenario de su tradición artística indígena semanifestó en el arte tequitqui, en el proceso del sincretismo los frailes dejaron cierta libertad expresiva a los artistas indígenas cuyo resultado fue ese nuevo arte. EI cual significa por un lado sincretismo cultural, dominio del otro, pero cierta rebel día a no perder del todo el lenguaje propio.

El arte tequitqui es una expresión coyuntural, de un momento histórico muy significativo para los indígenas mexicanos.

BIBLIOGRAFÍA

AlPEROVICH, M. S., "El número de habitantes de México en el periodo colonial", en Ensayos de historia de México. 7ạ , México, Ediciones de Cultura Popular, 1979.

Bermej o Serafín, Rita Teresita, Manual Gráfico de "Arte Tequitqui" en las esculturas de piedra, de los conjuntos conventuales franciscanos del siglo XVI, en el Estado de Puebla. México, 1998, Tesis, EDIMBA, 174 pp.

BEYER, Hermann, Mito y simbología del México antiguo. México, 1965.

BAUDOT, Georges, Pervivencia del mundo azteca en el México virreinal. México, UNAM, 2004.

CABRAL PÉREZ, I gnacio, Los símbolos cristianos. México, Trillas, 1995, $332 \mathrm{pp}$.

COLL, J. Oliva de, La resistencia indígena ante la conquista. 2a , México, Siglo XX, 1976, 284 pp.

FERnÁNDEZ GARCíA, Martha Raquel, Historia del concepto de "Arte Tequitqui". Tesis. UNAM, FFL, México, 1976, $480 \mathrm{pp}$.

FERNÁNDEZ, J ustino, Estética del arte mexicano. México, UNAM, 1972, $561 \mathrm{pp}$.

GALARZA, J oaquín, Los códices mesoamericanos. MéxiCO, UNAM, 1983, $150 \mathrm{pp}$.

HIEDEN, Doris, Mitología y simbolismo de la flora en el México prehispánico. México, UNAM, 1983, 176 pp. 
J OHANSSON, Patrick, La palabra de los Aztecas. Estructura del lenguaje pictográfico, México, Trillas, 1993, 247 pp.

KUBLER, George, Arquitectura mexicana del siglo XVI, New Haven, Yale University Press, 1948, 683 pp.

LEÓN PORTILLA, M., Los antiguos mexicanos. México, FCE, 1972, 198 pp.

MANRIQUE, J orge Alberto, "El trasplante de las formas artísticas españolas a México" en Actas del Tercer Congreso Internacional de Hispanistas. México, EI Colegio de México, 1969.

- La presencia de elementos iconográficos prehispánicos en el arte novohispano del siglo XVI. México, UNAM, 1979.

MAZA, Francisco de la, "La mitra mexicana de plumas de "el Escorial”, en Artes de México. México, núm. 137, 1960.

MORENO VILLA, J osé, La escultura colonial mexicana. México, El Colegio de México, 1942, 103 pp.

ReYes VAlerIo, Constantino, Arte indocristiano, escultura del siglo XVI. México, 1978.

RICARD, Roberto, La conquista espiritual de México. México, FCE, 1986, 491 pp.

SELER, Eduardo, Las representaciones de animales en los manuscritos mexicanos y mayas. México, INAH, 1986, $222 \mathrm{pp}$.

Toussaint, Manuel, Arte colonial en México. México, UNAM, 1974 3a., 303 pp.

VARGAS LUGO, Elisa, Las portadas religiosas de México. México, UNAM, 1969, 367 pp. 
